\title{
Design and flight test of a linear parameter varying flight controller
}

\author{
Christian Weiser $^{1}$ (D) Daniel Ossmann ${ }^{2} \cdot$ Gertjan Looye $^{1}$
}

Received: 2 March 2020 / Revised: 27 May 2020 / Accepted: 29 July 2020 / Published online: 28 August 2020

(c) The Author(s) 2020

\begin{abstract}
Future aircraft generations require improved performance and efficiency to enable a reduced environmental footprint. To acquire this goal, for example new material and wing concepts are perused at the moment by the aircraft industry. These developments, which include aspects such as over-actuation and lowly damped flexible modes, give rise to more complex, multi-objective control problems. One candidate method, which delivers a solution to these problems for the whole flight envelope, is linear parameter varying (LPV) control. It naturally incorporates the controller scheduling in the synthesis process, guarantees stability and robustness over the entire parameter envelope, and enables intuitive multi-objective, multipleinput multiple-output (MIMO) controller designs. This paper proves the concept of LPV control in practice: The paper presents and discusses the LPV controller design process, simulation results, motion simulator test and finally, the in-flight validation of the control system on a Cessna Citation II aircraft. The developed inner loop controller structures are inspired by classical flight controllers used on state-of-the-art fly-by-wire airliners. The longitudinal aircraft motion is augmented with load-factor command and the lateral motion controller features a roll rate command with attitude hold behavior. The control laws are validated in flight by automated and actual pilot inputs with respect to functionality, flying and handling qualities. Test results are encouraging with the provided key findings and lessons learned aiming to provide a simplification for future LPV flight controller development and testing campaigns.
\end{abstract}

Keywords LPV $\cdot$ Robust control $\cdot$ Flight testing

\section{Introduction}

The design of flight control laws for transport aircraft is still mostly relying on classical control methods, such as proportional-integral-derivative controllers in combination with straightforward gain scheduling. This is due to the stringent certification requirements but also due to the good performance characteristics of these classical control approaches. Future aircraft controller designs will, however, need to incorporate multi-objective design problems, as well as tackle their multiple-input multiple-output (MIMO) nature.

Christian Weiser

christian.weiser@dlr.de

Daniel Ossmann

daniel.ossmann@hm.edu

Gertjan Looye

gertjan.looye@dlr.de

1 German Aerospace Center (DLR), Oberpfaffenhofen, Germany

2 University of Applied Sciences, Munich, Germany
One modern control design technique, which showed already promising results in flight is linear parameter varying (LPV) control $[16,17]$. In addition to robustness against model uncertainties, the LPV technique results in a controller which is already scheduled over flight envelope parameters [1]. Moreover, the LPV design can be seen as an extension to a previously conducted $\mathrm{H}_{\infty}$ control test campaign, which was performed using an unmanned aerial vehicle [25].

For this work, a CS 25 certified Cessna Citation II is chosen as testbed. On this aircraft, extensive experience of testing different fly-by-wire control laws has been gained during previous test campaigns for (Incremental) non-Linear Dynamic Inversion control [8]. Thus, the aircraft is a perfect test bed to develop new control algorithms on real aircraft.

The contribution of this paper is to extensively present the whole development process of an LPV controller, from its initial model based controller synthesis [26] to the inflight validation [27]. Therefore, LPV control for both axes is assessed within this work. LPV controller synthesis is employed to derive robust and scheduled control laws for both longitudinal and lateral augmentation of the test aircraft. The 
LPV technique is an advancement of classical robust control approaches and therefore allows achieving satisfactory robustness against model uncertainties via the closed loop shaping technique. Sufficient robustness with respect to model uncertainties and variations in the weight and balance configuration is considered in the control design. Moreover, the additional performance objectives defined herein are satisfactory handling qualities for augmented flight. Specifications for satisfactory flying qualities defined in [24] are considered. A strategy on how these design requirements are transformed into frequency-domain weighting filters used by the LPV closedloop shaping synthesis is discussed. For testing and evaluation of the controller, the DLR Robotic Motion Simulator within the Institute of System Dynamics and Control [3] is used for software in the loop (SIL) evaluations before transferring the control laws to the test aircraft for Hardware in the Loop (HIL) testing and flight experiments.

Firstly, an introduction of the used means of LPV controller synthesis is given in Sect. 2. For the design of the control laws, an LPV representation of the nonlinear aircraft model of the Citation II is obtained within Sect. 3. Following, an LPV controller is developed based on the gridded LPV model. Sect. 4 gives insight in the process of control law validation leading towards the flight testing as well as test execution and a summary of results.

\section{LPV control synthesis}

In this section, the LPV approach used for control design is described. As specifications on the longitudinal and lateral flying qualities are given in [24] already in the frequency domain, this is a promising starting point to derive a closed loop shaping process, which results in good handling qualities. $\mathrm{H}_{\infty}$ control [23] is a useful method as it allows to 'shape' the closed loop frequency response. As extension to this, LPV control synthesis permits to use a similar scheme for LPV models [18, 28]. A considerable advantage of the resulting controller is the ability to be directly scheduled with the varying parameter vector $\rho$ while guaranteeing stability and performance for all parameter trajectories within the bounds of its defined values and rate of change.

Firstly, LPV models are introduced in Eq. (1) similar to Linear Time Invariant (LTI) models with the addition that all four matrices are dependent on a scheduling parameter vector $\rho(t)$. Each entry of the parameter vector $\rho(t)$ is a function of time with allowable trajectories, defined by limits on each parameter as well its derivative.

$G_{\rho}:\left\{\begin{array}{l}\dot{x}(t)=A(\rho(t)) x(t)+B(\rho(t)) u(t) \\ y(t)=C(\rho(t)) x(t)+D(\rho(t)) u(t)\end{array}\right.$

To explain the idea of LPV control, the induced $L_{2}$ norm of an LPV system $G_{\rho}$ from input $d$ to output $z$ over all allowed trajectories in a set $P$, assuming zero initial conditions, is defined in [28][Def. 3.3.1] as

$\left\|G_{\rho}\right\|_{\infty}=\sup _{d \in L_{2} \backslash 0 \rho \in P} \frac{\|z\|_{2}}{\|d\|_{2}}$.

The induced $L_{2}$ norm expresses the maximum input-output gain of $G_{\rho}$, i. e., the largest amplification of $L_{2}$ input signals over all frequencies, input/output directions, and admissible parameter trajectories. For the design of linear parameter varying control laws, a closed loop interconnection including a weighting structure as seen in Fig. 1 is introduced to shape the closed loop response of the system. In the generalized plant of Fig. 1 the inputs are the reference signal $r$, the input disturbance $d_{i}$, and the output disturbance $d_{o}$. Outputs are the weighted control effort $u$ and the weighted error $e=r\left[\begin{array}{ll}W_{h} & \underline{0}\end{array}\right]-y$, including the tracking error. This tracing error is explicitly weighted via $W_{h}$ to allow for a two degree of freedom controller design. Note that $W_{h}$ is typically a single-input single-output weighting filter as in the problems considered herein there is only one reference signal while multiple measurement signals are available. This generic structure serves as base for both the longitudinal and lateral axis. The resulting input-output map for the control design is given by

$\left[\begin{array}{l}z_{e} \\ z_{u}\end{array}\right]=\left[\begin{array}{cc}W_{e} & 0 \\ 0 & W_{u}\end{array}\right] P\left[\begin{array}{ccc}1 & 0 & 0 \\ 0 & W_{d_{i}} & 0 \\ 0 & 0 & W_{d_{o}}\end{array}\right]\left[\begin{array}{c}r \\ d_{i} \\ d_{o}\end{array}\right]$

with

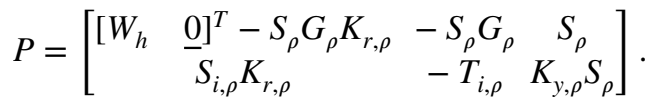

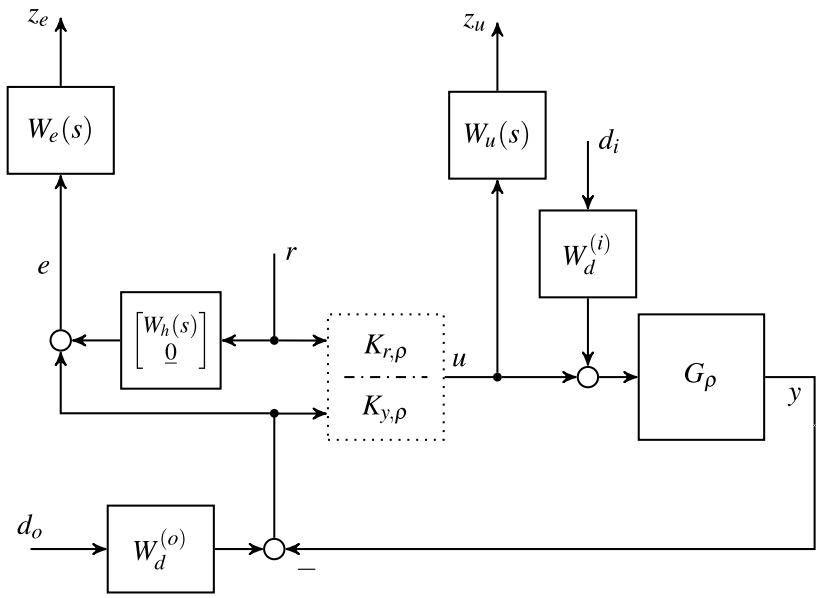

Fig. 1 Generic weighting structure used for the longitudinal and lateral controller design 
In Eq. (3) $K_{y, \rho}$ is the feedback part and $K_{r, \rho}$ the feed-forward part of the controller, $G_{\rho}$ is the transfer matrix from command inputs to plant outputs. Further, $S_{\rho}=\left(I+G_{\rho} K_{y, \rho}\right)^{-1}$ is the sensitivity function, and $S_{i, \rho}=\left(I+K_{y, \rho} G_{\rho}\right)^{-1}$ and $T_{i, \rho}=K_{y, \rho} G_{\rho}\left(I+K_{\rho} G_{\rho}\right)^{-1}$ are the input sensitivity and input complementary sensitivity functions, respectively $T_{r, \rho}=K_{r, \rho} G_{\rho} S_{\rho}$ complimentary sensitivity on reference signal. $W_{e}(s)$ and $W_{u}(s)$ are the diagonal output weighting matrices, and $W_{d_{i}}$ and $W_{d_{o}}$ are the diagonal input weighting matrices to be chosen in the design process. Note that the aircraft models $G_{\rho}$ are scaled as proposed in [23] by input-output scaling. As indicated in Fig. $1, W_{e}(s), W_{h}(s)$ and $W_{u}(s)$ are selected as dynamic filters, while all other filters are constant. $W_{h}(s)$ denotes a handling quality filter in the form of Eq. 5 and allows to set a design response in terms frequency $\omega_{h}$ and damping $\zeta_{h}$.

$W_{h}=\frac{\omega_{h}^{2}}{s^{2}+\omega_{h} \zeta_{h} s+\omega_{h}^{2}}$.

The entries for the shaping filter $W_{u}$ are selected as first-order transfer functions with unit gain up to the available bandwidths $\omega_{a, i}$ for $i=1, \ldots, n$ of each control input and approximately differentiating behavior beyond that frequency. In $W_{e}$ only the first element is dynamic to weight the tracking behavior, while all other channels are set to constant values to weight the outputs. As in this paper integral behavior is demanded in the tracking channel, the choice for the first entry is a first-order transfer function with approximately integral behavior up to the desired bandwidth $\omega_{b}$, which reduces the sensitivity up to this defined bandwidth. The weighting filters are selected in such manner that the general design goals for pitch and roll control, which are taken from the level 1 flying quality specifications for piloted aircraft [24], will be met. The demands for the flying qualities are defined in frequency domain for both longitudinal and lateral motion. For example, for design of the weighting filters of the pitch controller the control anticipation parameter (CAP) is used as a design parameter and sets a desired short period (SP) frequency. A more detailed description can be found in Sect. 3.2. Further, the controllers shall meet common requirements for gain and phase margins $\left(6 \mathrm{~dB}, 45^{\circ}\right)$.

The resulting parameter dependent controller

$K_{\rho}=\left[\begin{array}{c|c}A_{K}(\rho, \dot{\rho}) & B_{K}(\rho) \\ \hline B_{K}(\rho) & D_{K}(\rho)\end{array}\right]$

is synthesized solving a convex optimization problem [29].

The obtained controller therefore minimizes the upper bound on the induced $L_{2}$-norm of the interconnection in Fig. 1 with inputs $\left[\begin{array}{lll}r & d_{i} & d_{o}\end{array}\right]^{T}$ and outputs $\left[\begin{array}{ll}z_{e} & z_{u}\end{array}\right]^{T}$
$P \stackrel{S}{=}\left[\begin{array}{c|ccc}A(\rho) & B_{11}(\rho) & B_{12}(\rho) & B_{2}(\rho) \\ C_{11}(\rho) & D_{1111}(\rho) & D_{1112}(\rho) & 0 \\ C_{12}(\rho) & D_{1121}(\rho) & D_{1122}(\rho) & I \\ C_{2}(\rho) & 0 & I & 0\end{array}\right]$.

Assumptions necessary to solve this state feedback and observer problem (no full state feedback available) are described in [21].

As proven in [21, 28], an output feedback controller $K$ that stabilizes the closed loop interconnection $G_{c l, \rho}=\mathcal{F}_{L}(P, K)$ and guaranteed $\left\|G_{c l, \rho}\right\|<\gamma$ can be found if there exist symmetric positive definite matrix functions $X: \mathbb{P} \rightarrow \mathbb{R}^{n \times n}$ and $Y: \mathbb{P} \rightarrow \mathbb{R}^{n \times n}$ such that $\forall(\rho, \dot{\rho}) \in \mathbb{P} \times \dot{\mathbb{P}}$

$$
\begin{aligned}
& {\left[\begin{array}{cc}
X_{\rho} & \frac{1}{\gamma} I \\
\star & Y_{\rho}
\end{array}\right] \prec 0,} \\
& {\left[\begin{array}{ccc}
\Lambda_{X}-B_{2} B_{2}^{T} & X_{\rho} C_{11}^{T} & \frac{1}{\gamma}\left(B_{1}-B_{2}\right) D_{112} \bullet \\
\star & -I & \frac{1}{\gamma} D_{111} \bullet \\
\star & \star & -I
\end{array}\right] \prec 0,} \\
& {\left[\begin{array}{ccc}
\Lambda_{Y}-C_{2}^{T} C_{2} & Y_{\rho} B_{11} & \frac{1}{\gamma}\left(C_{1}^{T} C_{2}^{T} D_{11 \cdot 2}\right) \\
\star & -I & \frac{1}{\gamma} D_{11 \cdot 1}^{T} \\
\star & \star & -I
\end{array}\right] \prec 0}
\end{aligned}
$$

where $\star$ denotes symmetric completion and

$$
\begin{aligned}
& \Lambda_{X}(p, q) \\
& \quad:=X\left(A-B_{2} C_{12}\right)^{T}+\left(A-B_{2} C_{12}\right) X-\left.\sum_{i=1}^{n_{\rho}} \frac{\partial X}{\partial \rho_{i}}\right|_{p} \dot{\rho}_{i}
\end{aligned}
$$

$\Lambda_{Y}(p, q)$

$$
:=Y\left(A-B_{12} C_{2}\right)^{T}+\left(A-B_{12} C_{2}\right) Y-\left.\sum_{i=1}^{n_{\rho}} \frac{\partial X}{\partial \rho_{i}}\right|_{p} \dot{\rho}_{i} .
$$

As Eq. 9 also depends on the rate of change in the parameter $\dot{\rho}$, for the search of the functional relations $X(\rho)$ and $Y(\rho)$ mth order polynomial base functions of the form

$X(\rho)=X_{0}+\rho_{1} \cdot X_{11}+\rho_{1}^{2} \cdot X_{12}+\cdots+\rho_{n}{ }^{m} X_{n, m}$

are selected [29]. The choice of the base function parameters is up to the designer. It is useful to choose the base functions as simple as possible, as the number of unknowns in these functions correlates to the unknowns in the Linear Matrix Inequalities (LMIs) in Eq. 8 and therefore increases problem complexity. The obtained solutions for $X(\rho)$ and $Y(\rho)$ allow to specify a controller $K_{\rho}$ according to Eq. 6. A detailed calculation of the four controller matrices based on $X(\rho)$ and $Y(\rho)$ can be found in [29, Sect. 4].

Design examples for LPV controllers are described in literature, for example in $[19,29]$. The LPVTools MATLAB 


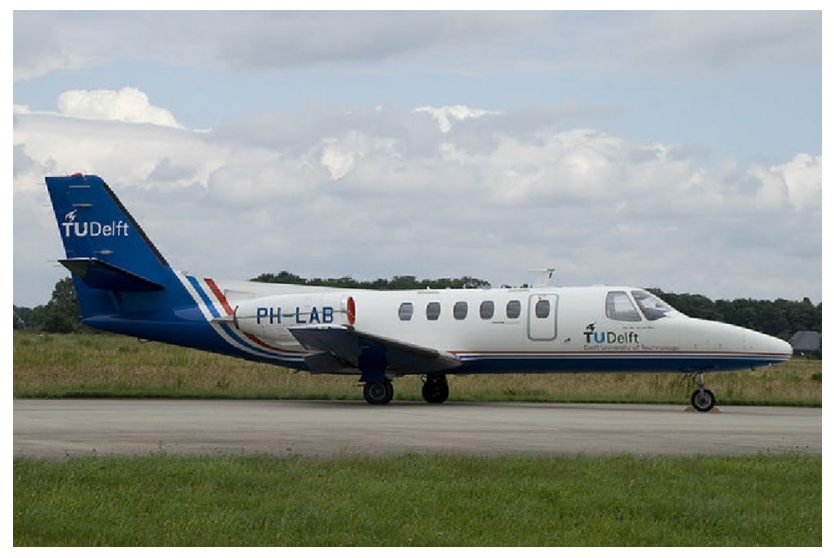

Fig. 2 Cessna model 550 citation II research aircraft PH-LAB [13]

Table 1 Basic parameters of Citation II aircraft

\begin{tabular}{ll}
\hline Parameter & Value \\
\hline Max. Take Off Weight & $6.6 \mathrm{tons}$ \\
Cruise Speed & $385 \mathrm{kts}$ \\
Ceiling & $43,000 \mathrm{ft}$ \\
Wing span & $15.9 \mathrm{~m}$ \\
\hline
\end{tabular}

toolbox [9] implements the solution to the LPV control problem in a similar way as described above.

\section{Modeling and control design}

For the model-based control design strategy a mathematical model of the considered test-aircraft is derived using an available non-linear simulation model. The aircraft, the process of deriving the LPV design model and finally, the designed controllers, including a first design-verification, are discussed in this section.

\subsection{Aircraft model}

The Cessna Citation II depicted in Fig. 2 is a research aircraft operated by the Delft University of Technology. The basic parameters of the aircraft are listed in Table 1.

A simulation model of the investigated aircraft was developed using the Delft University Aircraft Simulation Model and Analysis Tool (DASMAT) [12] and allows simulation and control design within the MATLAB/Simulink environment. The used DASMAT model was originally generated for a Cessna Model 500 Citation; nonetheless the modified simulation model shows good compliance with the Citation II [10]. The used aircraft model features standard six Degree of Freedom (DOF) nonlinear equations with aerodynamic lookup table data based on [12]. Note that the aircraft features relatively low aspect ratio paired with high stiffness due to a metal structure. Thus, the rigid body approximation holds especially in the envelope flown during controller assessment (medium altitudes and airspeeds) and effects like aeroelastic modes can be neglected. The actuators were modeled as second-order transfer functions according to [5]. The sensors are modeled as a combination of time delay, bias and noise. The basic flight control system is included and features a servo controller, which is able to set the actuator positions commanded by the flight control laws.

To obtain an LPV model of the Citation II aircraft, the nonlinear model is trimmed and linearized at a grid of operating points. Thus, a model according to Eq. 1 is obtained. As scheduling variable, dynamic pressure

$\bar{q}=\frac{\rho}{2} V^{2}$

is chosen, where $\rho$ is air density and $V$ true airspeed. For longitudinal and lateral dynamics, the LPV model of the full plant is fractioned into two models, as for controller design it is appropriate to consider the two axes as decoupled [6].

In the scheduling parameter $\bar{q}$ is considered in a range of $\bar{q} \in[2.5,6.5] \mathrm{kPa}$, which corresponds to a range of true airspeeds from $76 \mathrm{~m} \mathrm{~s}^{-1}$ to $129 \mathrm{~m} \mathrm{~s}^{-1}$ at an altitude of $4500 \mathrm{~m}$ (Flight Level (FL) 150)). The parameter rate is bounded to be within $\pm 500 \mathrm{~Pa} \mathrm{~s}^{-1}$. This corresponds to a rate of change in airspeed of approximately $7 \mathrm{~m} \mathrm{~s}^{-1}$ when at FL 450 with initial airspeed of $90 \mathrm{~m} \mathrm{~s}^{-1}$. For the controller development, an equally spaced parameter grid with 18 points was selected and verified against a denser grid of more than 50 points. Figure 3 depicts the poles of the open loop plant $4 \times 4$ Linear Time Invariant (LTI) models of the aircraft at four equidistantly chosen grid points, with dynamic pressure values of $[2.5,3.5,5.0,6.5] \mathrm{kPa}$. From the figure, the conjugate complex poles of SP mode can be read with frequencies ranging from 2 to $3 \mathrm{rad} \mathrm{s}^{-1}$ and a damping ratio of approximately 0.45 . The Dutch Roll (DR) motion is located at a similar frequency range, but with a damping ratio of slightly less than 0.2 , this mode is only poorly damped. The roll time constant $t_{r}$ can be read to a range from $0.33 \mathrm{~s}$ at highest dynamic pressure to $0.5 \mathrm{~s}$ at the lowest dynamic pressure value. The phugoid and spiral poles have large time constants and are located near $(0,0)$ in Fig. 3.

The following control design is carried out with the LPV models for longitudinal and lateral dynamics obtained here.

\subsection{Longitudinal control laws}

For the longitudinal control augmentation, load factor command $n_{z, \mathrm{cmd}}$ is selected as tracking reference for control design. The controller commands the maneuver load factor of the aircraft set by the pilot's pitch control input. 


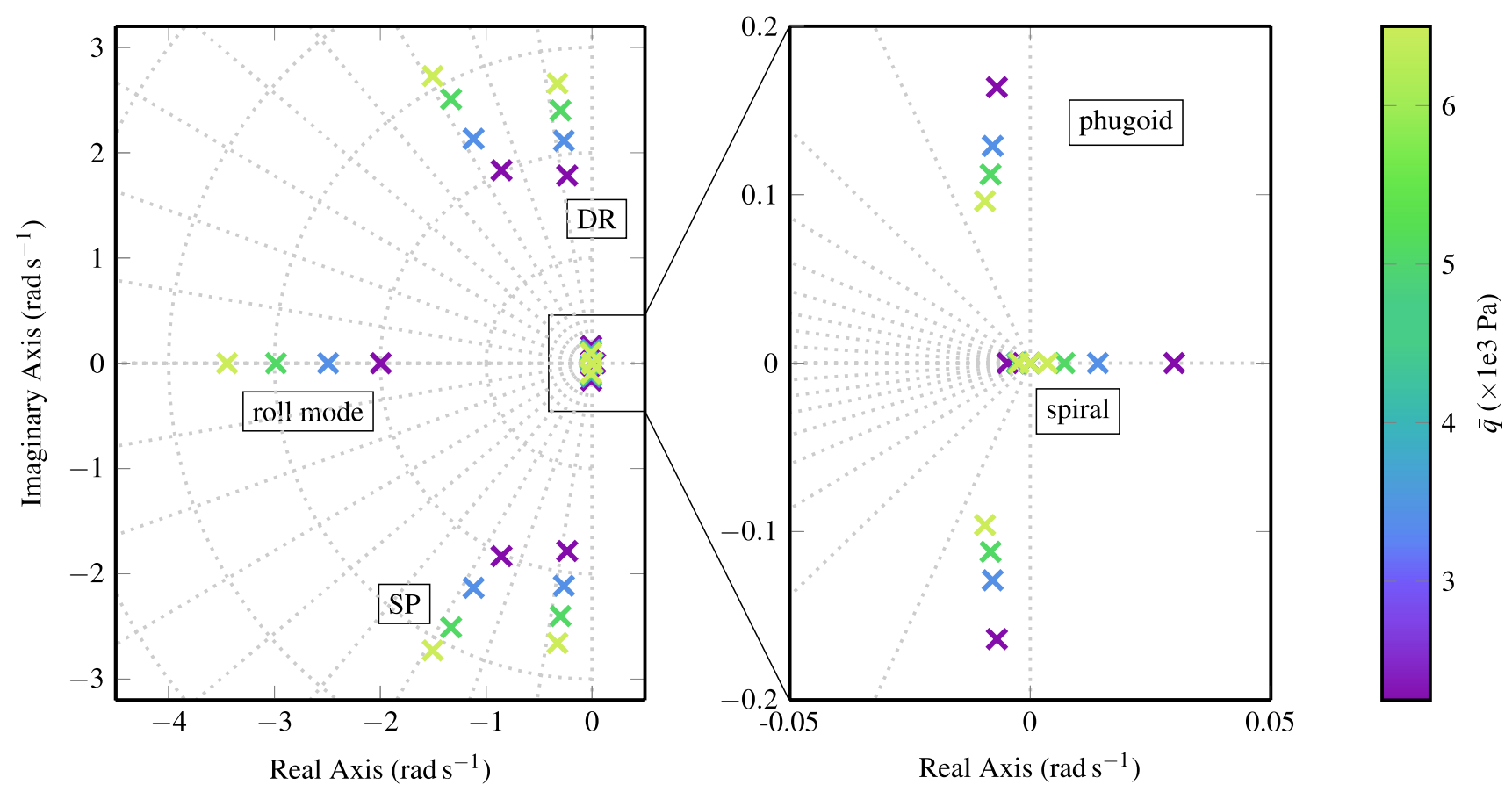

Fig. 3 Pole map of the open loop LTI models at 4 different values of $\bar{q}, 4$ th order longitudinal and 4th order lateral model poles (left hand side: roll mode real valued poles, Dutch Roll only slightly damped

As the $n_{z, b}$ sensor measurement includes gravity, the feedback needs to be corrected by the aircraft's pitch and roll attitudes $(\Theta, \Phi)$ :

$n_{z, \operatorname{man}}=n_{z, \mathrm{cg}} \frac{\cos (\Theta)}{\cos (\Phi)}$

This corrected value $n_{z, \text { man }}$ results in a value of $1 \mathrm{~g}$, independent of the aircraft's attitude and flight path. This design approach has the advantage that a zero command input results in an attitude hold behavior, which is convenient for augmented flight. Therefore, a neutral stick input is related to a $1 \mathrm{~g}$ flight with flight path angle hold. As the test aircraft is not equipped with an auto-throttle system, manual adjustment of the throttle is mandatory to keep the airspeed and dynamic pressure inside the test envelope bounds. To obtain a stable and fully controllable plant, control design only considers elevator input together with the SP model, with angle of attack and pitch rate as states and load factor $n_{z}$ as controlled plant output. Due to the missing auto-throttle, the 4th order longitudinal model is not fully controllable (attitude and path variables cannot be decoupled). For this reason, instead the 2nd order SP model is used for controller synthesis. When integrating the resulting SP controller into the full model, the result is a phugoid motion with two real poles of which one may be in the unstable region, but with a time constant larger than $30 \mathrm{~s}$. This leads to the requirement and SP with higher damping ratio, right hand side: zoomed in, real valued Spiral mode, which gets slightly unstable for lower airspeeds, Phugoid mode)

of manual adjustment of thrust settings accordingly to avoid stall or overspeed regions of the envelope.

The limits of the controlled output are $\pm 0.3 \mathrm{~g}$ for the commanded load factor. The design process for the maneuver load factor requires $r=n_{z \text {,man }}$, as the tracking reference variable. The measured outputs are the load factor in body $z$-axis and the pitch rate of the aircraft. Design goals for the longitudinal motion are defined in [24] via the control anticipation parameter (CAP), as well as a minimum SP damping of $\zeta=0.3$ and an optimal SP damping value of $\zeta=0.7$.

The CAP was originally defined in [4] and relates the immediate pitch acceleration to a control input and the steady state load factor which will be the result of a longitudinal control input:

$\mathrm{CAP}=\frac{\dot{q}\left(t=0^{+}\right)}{n_{\mathrm{z}, \infty}}=\frac{\omega_{S P}^{2}}{n_{z, \alpha}}$,

where $\omega_{S P}$ is the SP frequency and $n_{z, \alpha}$ the (stationary) load factor resulting from a change in angle of attack. The value of $n_{z, \alpha}$ is characteristic for each aircraft, thus only $\omega_{S P}$ can be influenced. The CAP has a goal value of one, which means that the pilot is able to determine the amount of stick input needed for a certain load factor easily from the pitch acceleration $\dot{q}_{0}$, which is a direct result of an elevator deflection $\eta$. The load factor $n_{z}$ in turn takes time to build up as it has two integral stages in between: 
$\eta \rightarrow \dot{q} \stackrel{\int}{\rightarrow} q \rightarrow \dot{\alpha} \stackrel{\int}{\rightarrow} \alpha \rightarrow n_{z}$,

where $q$ is the pitch rate and $\alpha$ the angle of attack. In case of a CAP smaller than one, the pitch acceleration after a control input is low and the pilot will have the tendency to underestimate the stationary load factor, thus giving higher pitch input as needed and overshooting the desired load factor.

The handling quality level 1 boundaries and results of the chosen controller design for load factor control can be seen in Fig. 4. The resulting CAP is in the level 1 region close to the optimal value for the whole design envelope, which was achieved in this case by a constant handling quality filter with a frequency of $1.75 \mathrm{rad} \mathrm{s}^{-1}$ and damping ratio of 0.8 . The load factor longitudinal controller features 12 states and shows integrating behavior up to a frequency of $2 \mathrm{rad} \mathrm{s}^{-1}$. Figure 5 depicts the sensitivity and complementary sensitivity functions of the load factor controller. The plots indicate a maximum frequency for reference tracking of $0.4 \mathrm{rad} \mathrm{s}^{-1}$. Figure 6 depicts singular value plots of the synthesized controller $K$ at four equally spaced grid points. It can be seen that until $2 \mathrm{rad} \mathrm{s}^{-1}$ the controller features integrating behavior, whereas constant/slightly increasing gain beyond until about $20 \mathrm{rad} \mathrm{s}^{-1}$ ensures robustness of the closed loop.

The time domain results of the linear $n_{z}$ command design exhibit rise times smaller than $4 \mathrm{~s}$ for low and smaller than

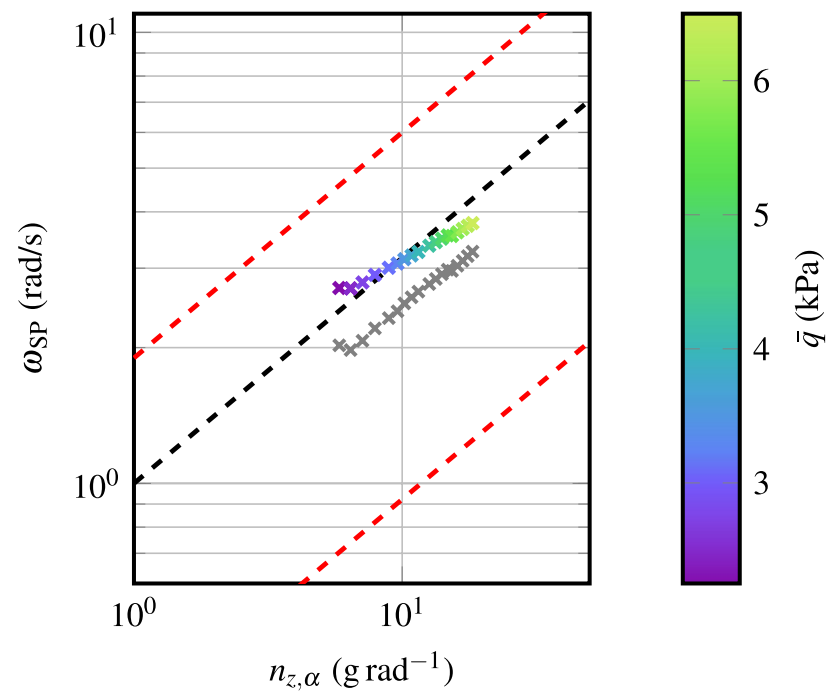

Fig. 4 Control anticipation parameter (CAP) for the $n_{z}$ control law throughout the flight envelope of the closed loop compared to the open loop ( $x$ ). Additionally, the ideal CAP $=1$ (- - - ) and level 1 flying qualities region boundaries (- - - ) according to [24] are depicted

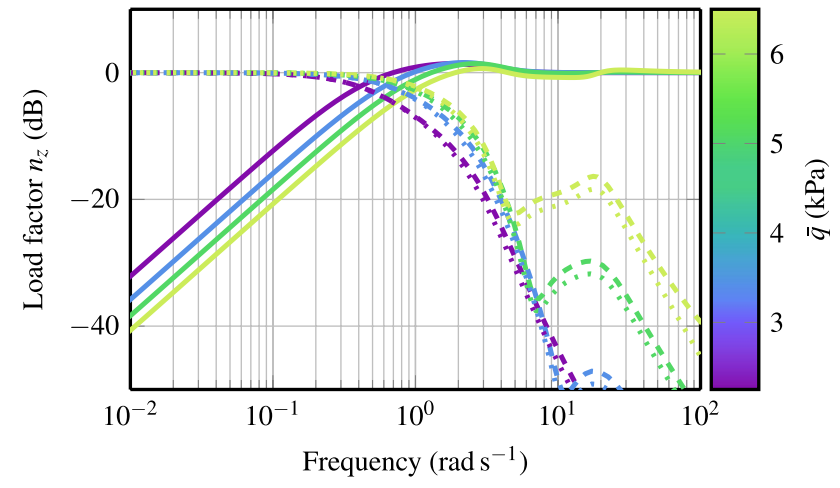

Fig. 5 Sensitivity function $S$ (-), complementary sensitivity function $T(---)$ and reference tracking function $T_{\mathrm{r}}(\ldots)$, depicted for the $n_{z, \mathrm{cmd}}$ control law

$2 \mathrm{~s}$ for high dynamic pressures. In terms of robustness, the multivariate multiple-input multiple-output (MIMO) margin has a minimum at the upper end of the parameter envelope with values of $6.4 \mathrm{~dB}$ and $41 \mathrm{deg}$ respectively, which can be considered as sufficient. The margins listed for the load factor control in Table 2 are a comparison of standard gain-, phase-, and delay-margins of loop cuts at the sensor or actuator signal(s) with more significant disk margins and robustness margins used in [22]. The disk margin is computed according to [2] and values for the phase of the disk margin vs. the scheduling parameter of the controller are depicted in Fig. 7. The drop of the margins for the high dynamic pressure region calls for a careful flight testing at the end of the envelope. As the maneuverability of the experimental flight control system (FCS) is limited by a relatively moderate power of the pitch servo, most maneuvers are flown in a low dynamic pressure region. When looking at frequencies, it can be noted that the frequency of the minimum disk margins in Fig. 7 is located several magnitudes above the

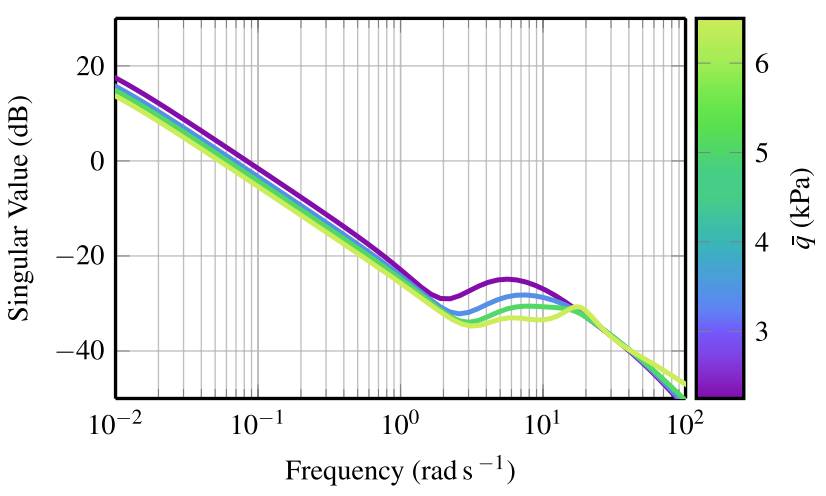

Fig. 6 Singular value plot of load factor controller at 4 different dynamic pressure values (equally spaced over the envelope) 
Table 2 Minimum margins of the load factor controller

\begin{tabular}{llll}
\hline Margin type & Freq. (rad/s) & Value & \\
\hline Gain & 247 & $13 \mathrm{~dB}$ & \\
Phase & 0.68 & $83 \mathrm{deg}$ & \\
Delay & 1.0 & $1.44 \mathrm{~s}$ & \\
I/O Disk & 117 & $11.8 \mathrm{~dB}$ & eq. 62 deg Phase Margin \\
MMIMO $^{\text {a }}$ & 0.81 & $6.4 \mathrm{~dB}$ & eq. 41 deg Phase Margin \\
\hline
\end{tabular}

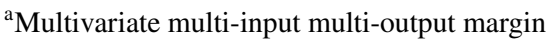

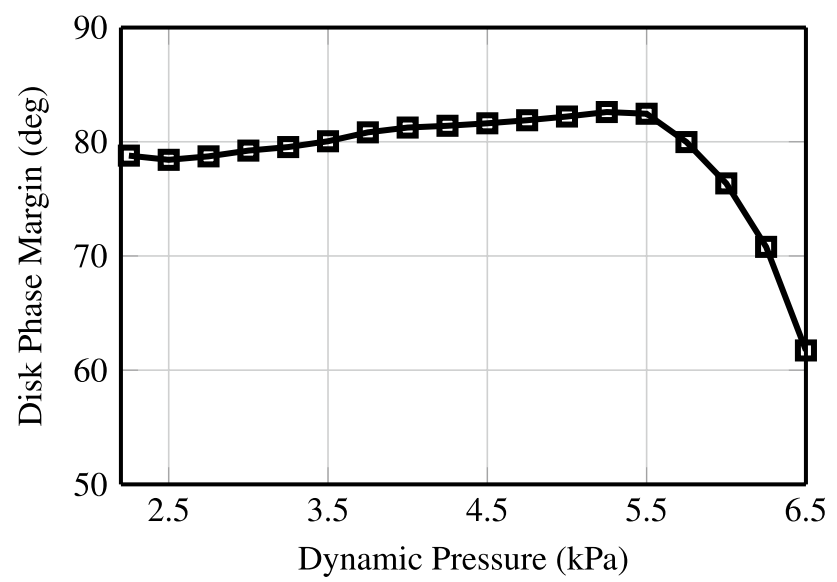

Fig. 7 Disk margin (phase) of the load factor controller w.r.t. scheduling parameter (dynamic pressure)

system bandwidth. This makes it uncritical even in the case of exceeding the flight envelope.

\subsection{Lateral control laws}

For the lateral inner loop the roll rate $p$ and angle of side slip $\beta$ are chosen as control variables. In the chosen setup, the experimental sidestick on the right hand pilot's seat allows the control of a roll rate up to a bank angle of $27^{\circ}$, beyond constant stick input is needed for higher bank angles. The maximum bank angle of $35^{\circ}$ shall never be exceeded and for a neutral stick the roll attitude shall return to $27^{\circ}$. The aircraft is not equipped with a yaw input on the experimental FCS, thus the yaw axis can be assessed via differential thrust settings or slip inputs triggered by the flight test crew.

For the inner loop control laws designed in this section, flying quality specifications for lateral axis [24] request a maximum time of $2 \mathrm{~s}$ for a $30 \mathrm{deg}$ bank angle change. Thus, a roll rate limit of $p_{\max }=15 \mathrm{deg} \mathrm{s}^{-1}$ is desirable, but due to limitations in fly-by-wire (FBW) actuation of the test aircraft only $p_{\max }=10 \mathrm{deg} \mathrm{s}^{-1}$ can be achieved.
The roll time constant $t_{r}$, which defines rise time of roll rate, shall be less than one second, which allows a sufficiently fast buildup of the roll rate following the pilot's lateral input. For the Dutch roll (DR) mode, specifications request a minimum damping of $\zeta=0.08$ and a minimum frequency of $\omega=0.4 \mathrm{rad} \mathrm{s}^{-1}$ as well as the product of damping and frequency to be at least $\zeta \omega=0.15 \mathrm{rad} \mathrm{s}^{-1}$.

The handling quality filter for the roll rate is implemented as a second order filter in the form of Eq. 5 with a frequency of $\omega_{S P}=5 \mathrm{rad} \mathrm{s}^{-1}$ and a damping of $\zeta=0.9$, to provide tracking of a commanded roll rate. The same form of filter, with a lower corner frequency, is chosen for the angle of sideslip channel. For both filters the performance weight on the tracking error is represented by a transfer function with integrating behavior up to a frequency of $12 \mathrm{rad} / \mathrm{s}$, which is sufficiently lower than the actuator bandwidth of $30 \mathrm{rad} / \mathrm{s}$. The actuator weights have differentiating behavior above the actuator bandwidth. All other weights are selected as constants. The resulting sensitivity and complementary sensitivity functions are depicted in Fig. 8. For both reference variables, nearly parameter independent behavior has been achieved, which results in similar aircraft responses for the roll motion over the whole envelope. Roll rate is tracked up to a frequency of $8 \mathrm{rad} \mathrm{s}^{-1}$ and angle of sideslip up to $1 \mathrm{rad} \mathrm{s}^{-1}$, above this frequency tracking accuracy diminishes due to higher prioritized yaw damping. The lateral controller has a number of 20 internal states.

Figure 9 shows the closed loop poles of the controlled LPV system versus the poles of the uncontrolled LPV plant. According to the previously explained tracking behavior, it can be clearly seen that a unique roll time constant for the full envelope is generated. This ensures similar times for the build-up of roll rate independent of the dynamic pressure, thus the pilot can expect similar behavior of the aircraft's roll motion without considering the actual airspeed and altitude. Moreover, an increased damping of the DR motion is achieved when comparing the closed loop with open loop poles.

Furthermore, Fig. 10 depicts the singular values over frequency of the resulting LPV lateral inner loop controller. Up to the DR frequency all curves show similar, integrating behavior whereas above this frequency, until about $10 \mathrm{rad} / \mathrm{s}$ the dependency on the value of the scheduling parameter can be seen in the controller gain. Figure 11 depicts the phase of the minimal disk margin of the lateral controller is depicted. For the comparison of classical gain / phase margins with the robustness margin computations introduced in Sect. 3.2, the values shown in Table 3 are calculated. With a minimum of $4.2 \mathrm{~dB}$, sufficient robustness even against simultaneous variations in all channels is ensured. 

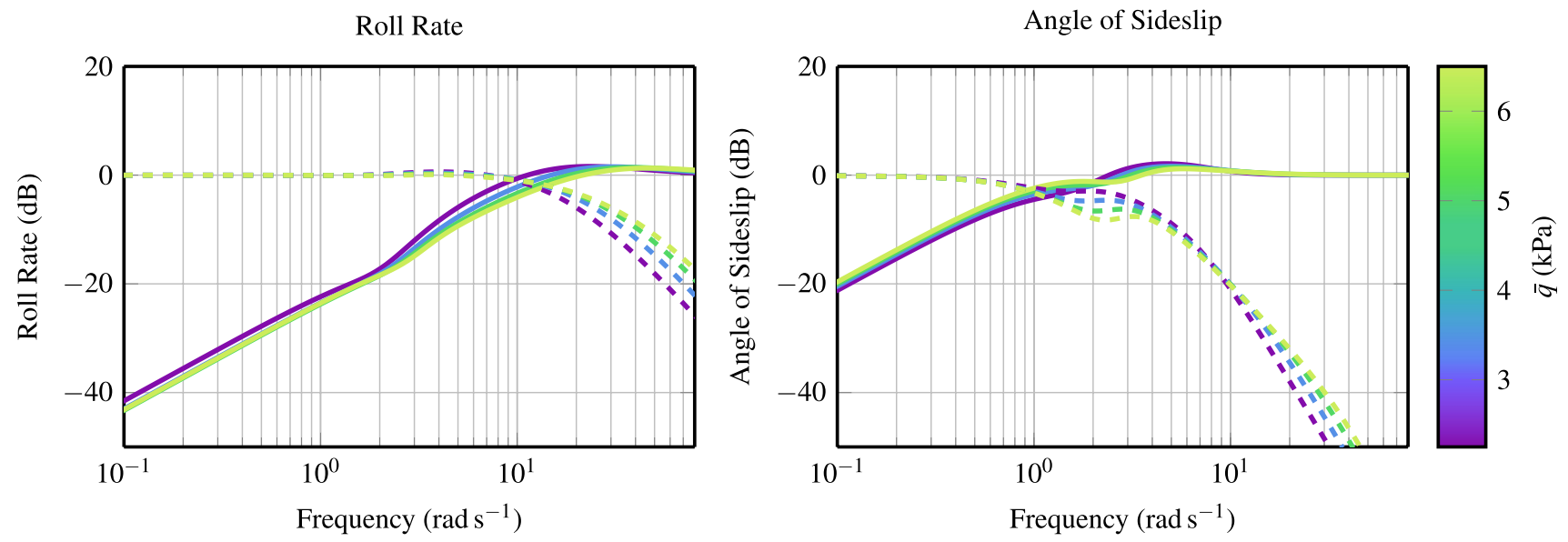

Fig. 8 Sensitivity function $S(-)$ and complementary sensitivity function $T(-=-)$ ) of the lateral dynamics

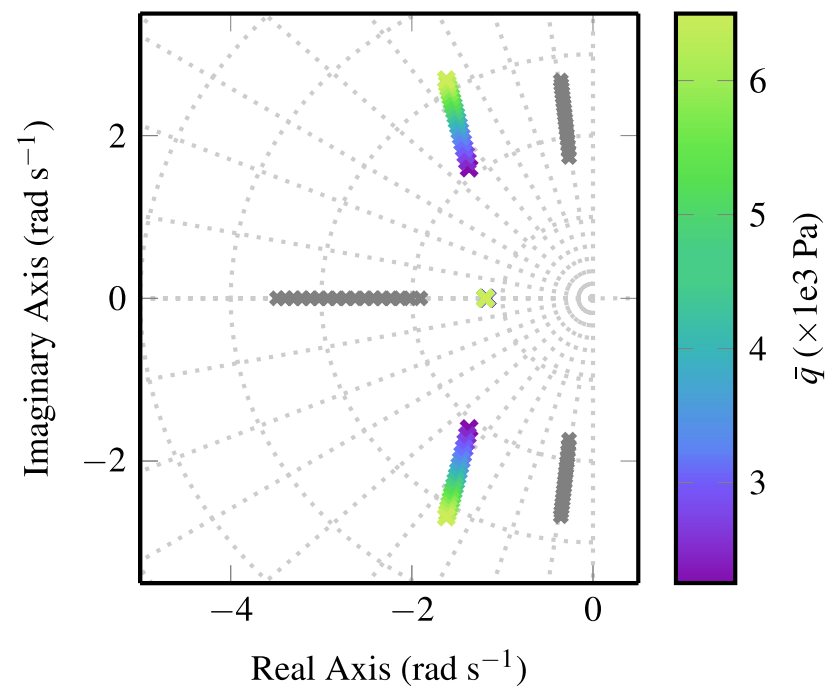

Fig. 9 Poles of lateral open loop (*) and closed loop ( $x$ ). The Dutch Roll shows increased damping ratio for the closed loop and roll time constant is clipped to only one value for the whole parameter envelope in closed loop

\section{Controller validation}

This section gives an overview of the means of control law validation, staring with SIL simulations, then moving to integration of the algorithms onboard the Cessna Citation research aircraft leading to flight testing.

\subsection{Software in the loop verification}

For verification of the designed control laws, an extensive simulation campaign has been performed, including nonlinear simulation on the DLR Robotic Motion Simulator

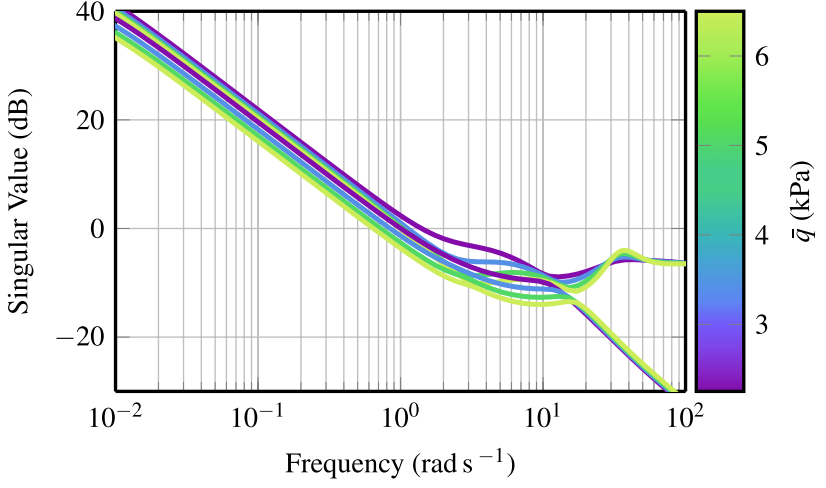

Fig. 10 Singular value plot of the lateral controller, displayed at 4 equidistantly spaced scheduling points

(RMS). For this first controller verification step, a set of different maneuvers, e.g., step-like commands and augmented piloted flights, have been carried out. Additionally, changes in the operating point have been used to verify smooth transitions of the controlled aircraft between the test points.

The Institute of System Dynamics and Control's RMS [3] has been used as a platform for flight test preparation via non-linear simulations. The RMS is a six degree of freedom industrial robot with an additional linear axis, as seen in Fig. 12. The simulator seats a single pilot and can be equipped with aircraft controls and virtual reality glasses in order to provide the user with a realtime response in terms of accelerations, body rates and attitudes. The pilot input, given via sidestick and thrust levers, is processed in the main simulation model and its 6 DOF outputs are delivered as motion command inputs to the RMS. Filtering algorithms ensure the gravity 


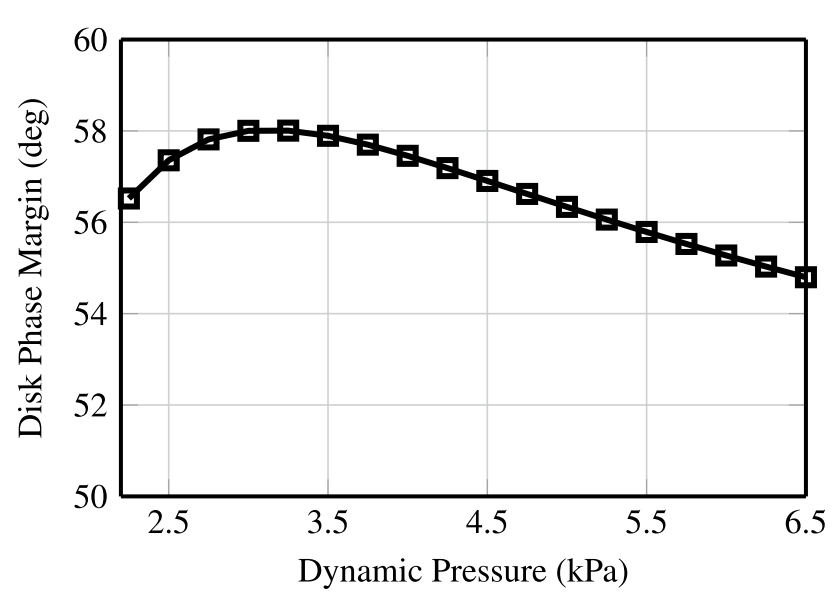

Fig. 11 Minimum disk margin (phase) of the lateral control loop w.r.t. scheduling parameter

Table 3 Minimum margins of the lateral control loop

\begin{tabular}{llll}
\hline Margin type & Freq. (rad/s) & Value & \\
\hline Gain (I) $^{\mathrm{a}}$ & 1.38 & $11.5 \mathrm{~dB}$ & \\
Phase (I) & 0.45 & $73.8 \mathrm{deg}$ & \\
Gain (O) & 1.72 & $10.8 \mathrm{~dB}$ & \\
Phase (O) & 0.47 & $70.2 \mathrm{deg}$ & \\
Delay (I/O) & 1.72 & $0.54 \mathrm{~s}$ & \\
Disk (I) & 1.21 & $11.3 \mathrm{~dB}$ & eq. $59.5 \mathrm{deg}$ Phase Margin \\
Disk (O) & 1.31 & $10.0 \mathrm{~dB}$ & eq. $54.8 \mathrm{deg}$ Phase Margin \\
MMIMO $^{\mathrm{c}}$ & 1.35 & $4.2 \mathrm{~dB}$ & eq. $26.8 \mathrm{deg}$ Phase Margin \\
\hline
\end{tabular}

${ }^{\mathrm{a}}$ Minimum margin on all input loop cuts

${ }^{\mathrm{b}}$ Minimum margin on all output loop cuts

${ }^{\mathrm{c}}$ Multivariate multi-input multi-output margin

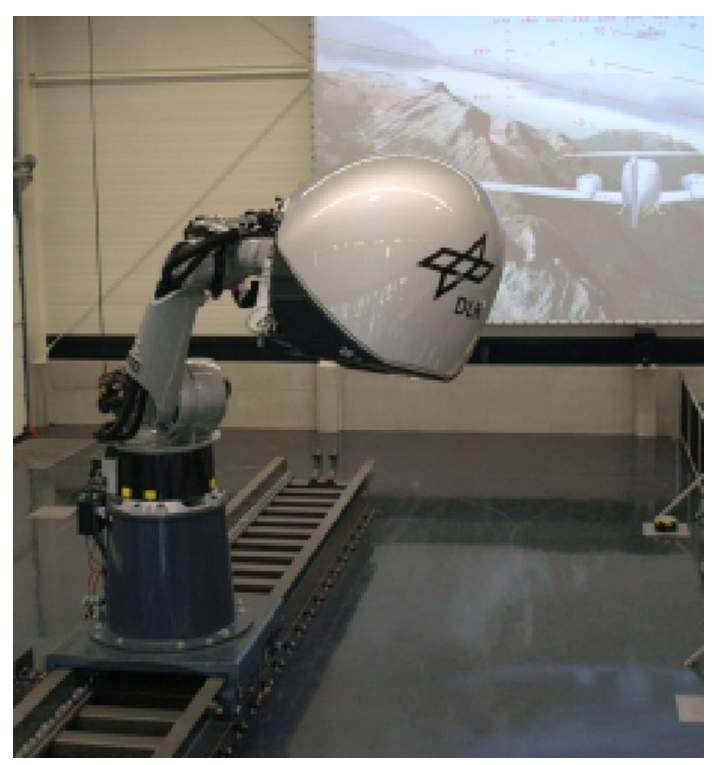

Fig. 12 Robotic motion simulator at the DLR Institute of system dynamics and control [3] vector always points in the direction of the stationary acceleration vector. Further, higher frequency accelerations are represented via translation and rotation of the gondola seen in Fig. 12. The SIL setup features a distributed computing environment, which consists of the above described RMS, pilot controls, the aircraft model described in Sect. 3 and detailed actuator models, which include the behavior of the aircraft's auto-pilot servos. The experimental FCS behavior, sensor and sensor bus environment with similar characteristics (transport delays, signal update rates) as the test aircraft were included. For convenience a visualization system was added. As a computing infrastructure, i7 CPUs running windows OS were used. The communication between the subsystems was implemented via network protocols and, in contrast to the flight test middleware onboard the test aircraft, no error handling of real-time violations was implemented.

The experimental flight control computer on the test aircraft is able to execute the control laws in continuous time, thus no explicit discretization of the LPV controller has been performed. All non-linear closed loop simulations as well as the SIL experiments on the RMS, however, were performed with a communication frequency of $100 \mathrm{~Hz}$, the same frequency as used on the test aircraft. The SIL setup has been mainly used for purposes of

- closed control loop simulations with pilot and automated control commands;

- investigation of transient behavior during controller (de-) activation and operating point changes;

- procedure training for flight test crew.

After successful completion of the SIL testing campaign, the control software has been considered ready to be integrated into the DUECA distributed real-time computation framework [15] which is used on the test aircraft. After this step, the DUECA framework manages communication between sensor, actuation signals and the FCS.

\subsection{Test aircraft and control system}

The Cessna Citation PH-LAB in Fig. 2, jointly operated by TU Delft and the Dutch Aerospace Center (NLR), serves as a multi-functional research platform. The aircraft is certified according to CS25 specifications [7] for large airplanes and equipped with a conventional, fully reversible flight control system providing a fix-geared link between the pilot's controls and the control surfaces of the aircraft. Additionally, an autopilot which has authority over the primary flight controls (elevator, aileron and rudder) 


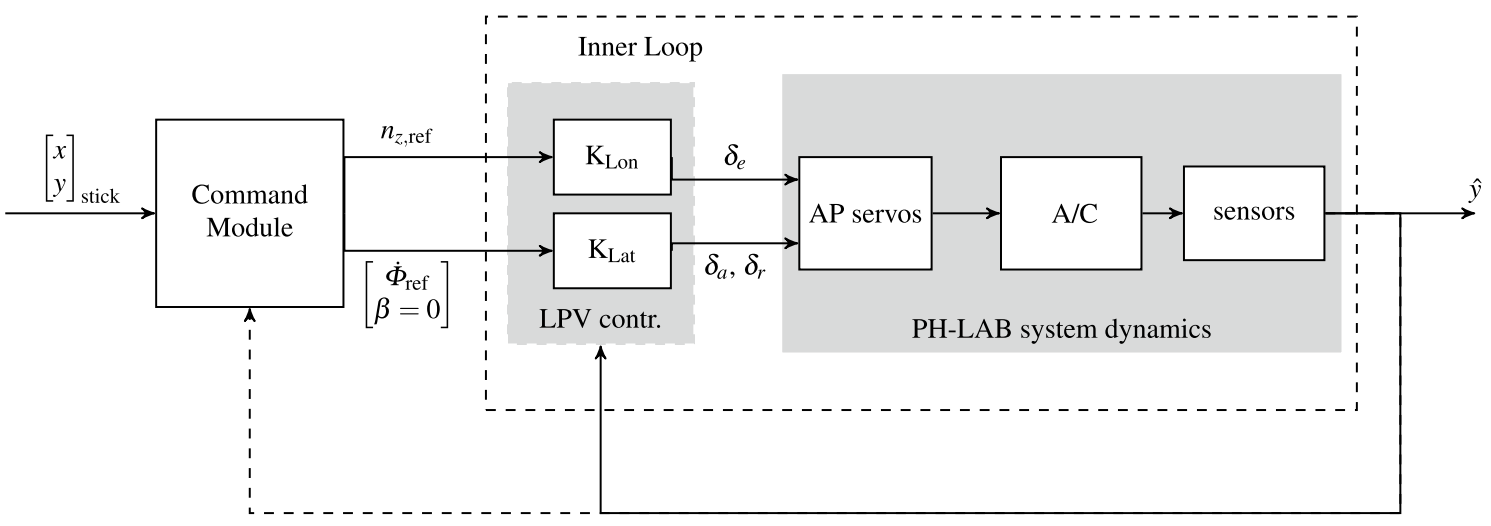

Fig. 13 Control system architecture

is available. The test aircraft is equipped with an experimental FBW system [30], which uses the autopilot servos as control actuators. This system also has been explicitly certified under CS 25 specifications [7]. In addition, a flight test instrumentation system [14] including further sensors (angle of attack, sideslip etc.) is available for data acquisition and logging. The hardware setup is described in more detail in Refs. [8, 14, 30].

Figure 13 shows a block diagram of the flight control software, including the LPV baseline controller, implemented on the test aircraft. As shown in Fig. 13, the command module translates the stick signal to the reference signals needed for the LPV inner loop. The described control system setup has been tested in previous experiments on the Citation aircraft $[8,11,20]$ and has been reused in the shown flight tests. Additionally, an attitude hold option via an outer loop can be activated to the lateral LPV inner loop control system. It additionally corrects for disturbances in roll attitude. As a result, it is possible to test a typical Airbus-like system behavior with attitude hold, or rate-command-only mode, which corresponds to a control philosophy in which the pilot needs to correct errors in attitude due to external disturbances.

The output signals of the LPV control feed the FBW servo control system [5] explained above. The servo system internally uses position feedback from the control surfaces to set the control surface deflections demanded by the LPV inner loop control laws.

\subsection{Test cases and test execution}

For in-flight validation a number of test cases were defined in order to verify all control design objectives. The flight test cases used for the test flights are described in Table 4.

Table 4 Overview of flight test maneuvers

\begin{tabular}{|c|c|c|}
\hline Maneuver & Synopsis & Objective \\
\hline Steady flight & $\begin{array}{l}\text { No control inputs, controller maintains system state at time } \\
\text { of activation }\end{array}$ & $\begin{array}{l}\text { Validate controller stability, check for transient free activa- } \\
\text { tion }\end{array}$ \\
\hline Pilot inputs & $\begin{array}{l}\text { Pilot commands roll or pitch, extending from small inputs } \\
\text { to full control authority }\end{array}$ & Validate system controllability and tracking performance \\
\hline Attitude control & $\begin{array}{l}\text { Pilot commands roll angles beyond } 27^{\circ} \text { of roll attitude, } \\
\text { max. roll attitude is limited to } 35^{\circ}\end{array}$ & Verify switching from rate to attitude control, verify limits \\
\hline Load factor capture & $\begin{array}{l}\text { Pilot and automatic inputs, fly several } 360^{\circ} \text { turns ascend- } \\
\text { ing and descending (change flight path angle with load } \\
\text { factor command in between) }\end{array}$ & $\begin{array}{l}\text { Verify tracking and stability of load factor command, } \\
\text { investigate flight path stability }\end{array}$ \\
\hline Automatic step inputs & $\begin{array}{l}\text { Step inputs are inserted into the system instead of pilot } \\
\text { stick force }\end{array}$ & $\begin{array}{l}\text { Generation of inputs with exact amplitude and step width } \\
\text { generates step responses to objectively quantify control- } \\
\text { ler performance }\end{array}$ \\
\hline Configuration changes & $\begin{array}{l}\text { Extension of flaps, gear during with no control input, after } \\
\text { transition to new configuration give small inputs }\end{array}$ & $\begin{array}{l}\text { Verify controller robustness against model uncertainties, } \\
\text { change in aircraft dynamics }\end{array}$ \\
\hline
\end{tabular}




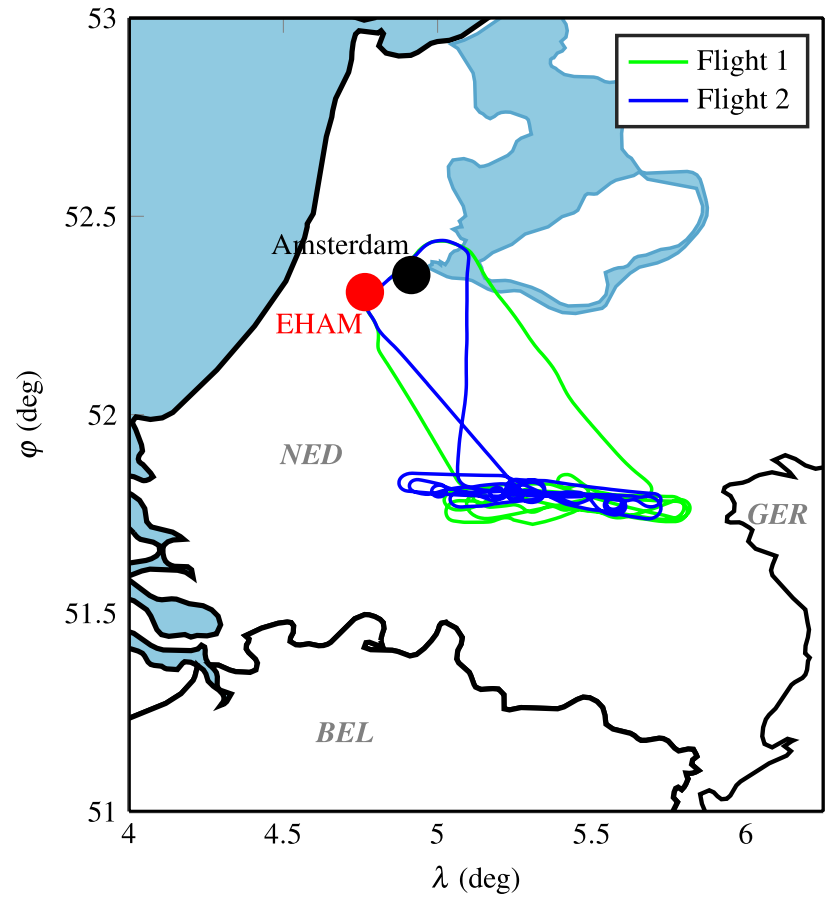

Fig. 14 Flight test trajectories

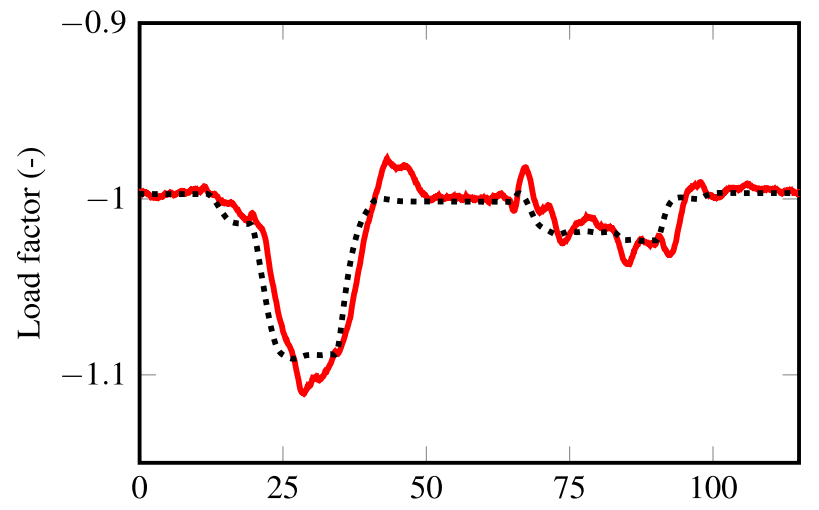

Resulting load factor command and response ( $\square$ ).

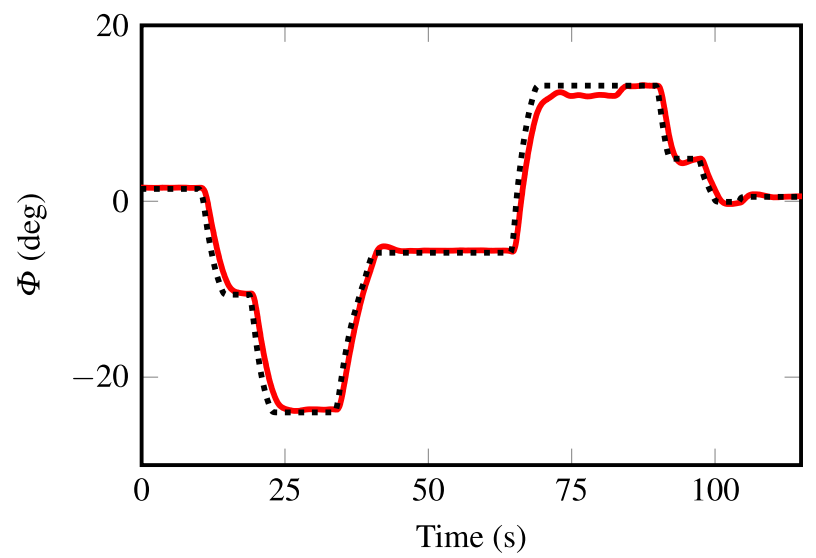

Integrated roll rate command and bank angle response ( - ).
The test flights were performed in February 2019 from Amsterdam Schiphol Airport. Two test flights were carried out in calm environmental conditions (no turbulence, constant wind of low magnitude) within a military testing airspace over the southern Netherlands (see Fig. 14). Both flights followed a similar scheme: after successful activation of the controller followed by careful maneuvers by the experimental pilot, the commands were slowly expanded to the full range limited by maximum control authority, including sweeps through the full range of the reference signal. An additional analysis of the flight test data is provided in [27].

To evaluate the tracking behavior and stability (rise time, settling time) the pilot was asked to command step inputs with small amplitudes followed by the same maneuver being repeated with automated input signals. Since the tested LPV method should provide robustness against model uncertainties, configuration changes were performed during flight to investigate stability during transition as well as responses after the configuration change.

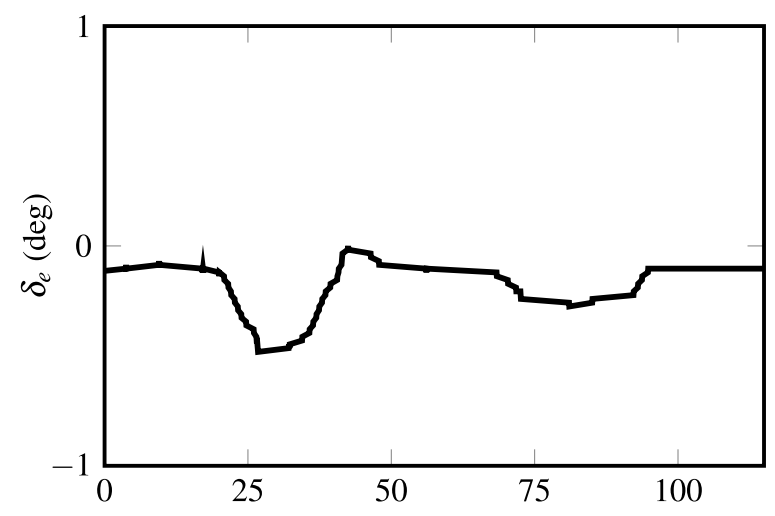

Elevator deflection relative to trim position.

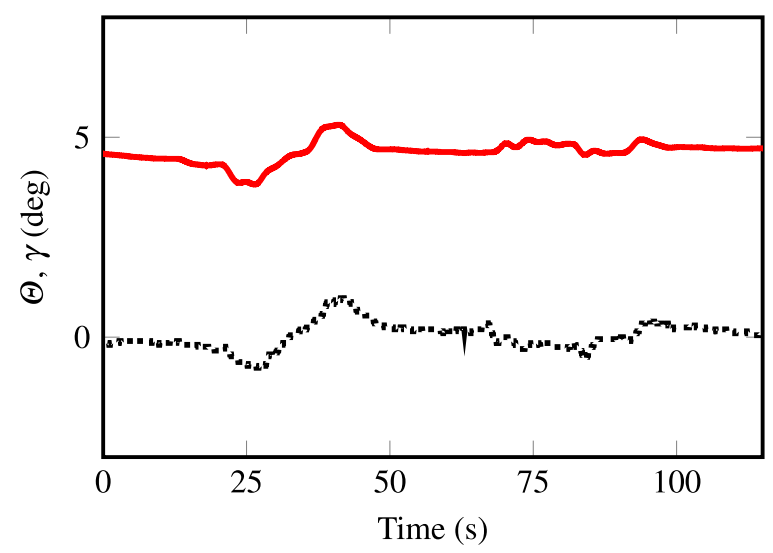

Pitch attitude (-) and flight path angle.

Fig. 15 Load factor response during a roll maneuver at $95 \mathrm{kts}$ VTAS 


\subsection{Flight test data}

A selection of test data is presented and discussed herein. Firstly, the responsiveness of longitudinal and lateral control channels is discussed, followed by the analysis of a simulated engine failure case as an example for robustness.

Longitudinal flight test results Due to the autopilot pitch servo actuator having limited authority, the load factor reference controller is validated during a bank maneuver. The load factor command response is displayed in Fig. 15. This setup allows load factor commands of multiple seconds to be fed without changing the aircraft's operating point in terms of airspeed and altitude. In Fig. 15, the pilot first banks to the left performing two steps and after approximately ten seconds of steady turning, steps in bank attitude to the right are performed. The left upper plot of Fig. 15 shows the associated load factor demand and resulting load factor for the maneuver. It can be seen, that the commanded load factor during the bank maneuver is tracked nicely by the longitudinal controller, keeping the flight path angle (left lower plot) at around zero degrees.

Lateral flight test results For verifying the lateral tracking performance, small step inputs are used. Figure 16 depicts an automatic step input given to the system with the respective aircraft and as control surface responses. The left diagram in Fig. 16 depicts roll and yaw rate as well as the reference signal for roll rate. The roll rate $(\dot{\Phi})$ follows the step in expected PT-1 like behavior with a time constant of approximately $1 \mathrm{~s}$ as designed for the closed loop (see Fig. 9). Yaw rate $(\dot{\Psi})$ (blue line) reacts without oscillations. Thus, the DR mode is sufficiently stabilized by the lateral MIMO control law. The right diagram shows the aileron and rudder deflections. As the lateral control law is designed for the multi-input multi-output problem with aileron and rudder as outputs, both control surfaces are deflected simultaneously. In a conventional control law, the roll input would develop an angle of sideslip first, which would then be corrected by the yaw controller. In this case, rudder deflection follows immediately after initiating the roll maneuver. Following, the developed sideslip has a maximum of $0.3 \mathrm{deg}$ after $4 \mathrm{~s}$ of the roll maneuver.

Simulated single engine failure Figure 17 shows the response of a (simulated) single engine failure. In this scenario the pilot manually decreased the power setting of one engine and at the same time increased the power of the remaining one to keep up constant level flying with constant indicated airspeed. The bottom left plot shows the actual engine power setting N1 whilst the top plots depict the response in angle of sideslip and roll attitude. The desired aircraft behavior is zero angle of sideslip and a steady roll attitude. Both goals are achieved by simultaneous deflections of rudder and aileron, which is the expected reaction of the lateral MIMO controller. With no angle of sideslip, the aircraft continues straight and level flying despite a differential thrust setting of $40 \%$ engine power on the left and $95 \%$ power on the right engine.

In addition to testing the different maneuvers listed in Table 4, the augmented inner loop control law was also enabled in the initial approach phase where aircraft configuration (flaps extended, gear down), deviated from the clean configuration used for the LPV controller synthesis. As the pilot was capable of maneuvering without difficulties even in landing configuration, a qualitative evidence for robustness against changes in the aerodynamic characteristics of the aircraft has been provided.
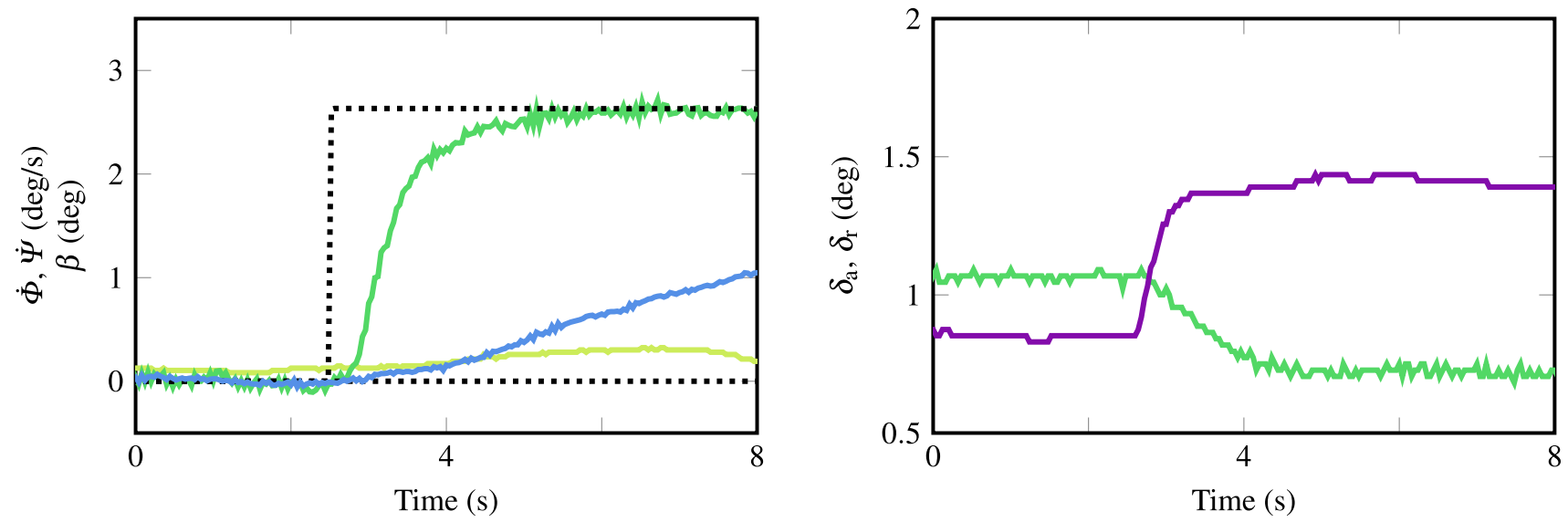

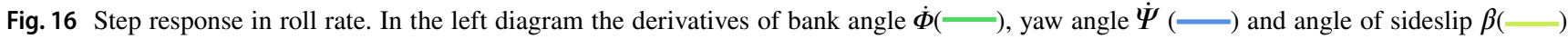
are depicted. The right diagram shows aileron $(-)$ and rudder $(-)$ deflections 

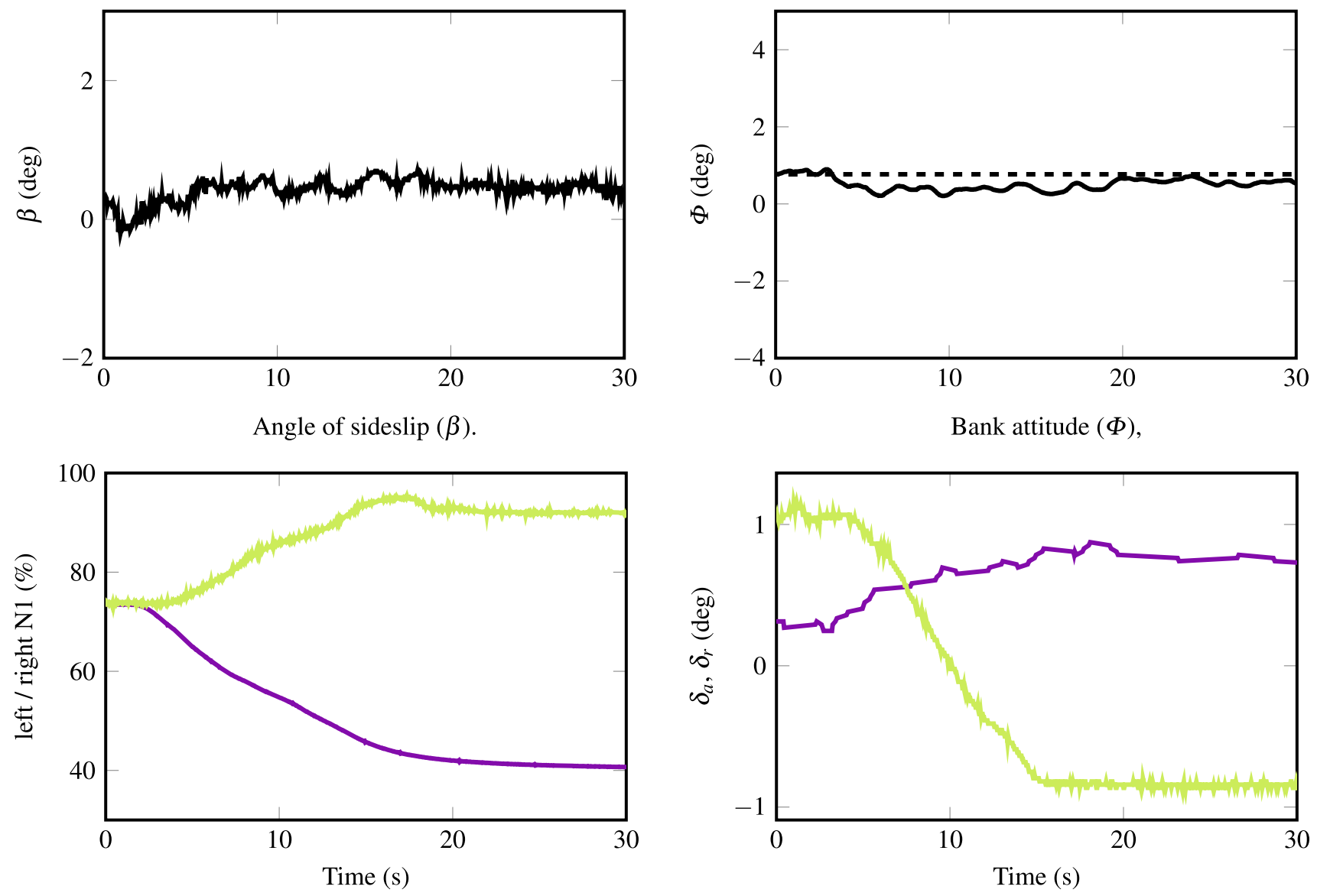

Left $(\longrightarrow) /$ right $(-)$ engine setting.

Deflections of aileron $(\longrightarrow)$ and rudder $(-)$.

Fig. 17 Simulated single engine failure: testing of lateral control laws by splitting the throttle settings during level flight

\subsection{Comparison of simulation and flight test data}

Figure 18 shows the comparison between flight test data presented in Fig. 15 and simulation data produced with recorded flight test commands as inputs. For re-simulation, the aircraft model was trimmed at the airspeed and altitude gathered from test execution. The inputs to the inner loop LPV commands in pitch and roll axis were recorded during flight and these values are now fed to the closed loop simulation model. The resulting outputs are depicted in Fig. 18 where dashed lines represent simulation data and solid lines the flight test data. For the simulation case, only roll rate command recorded from the flight test is fed to the inner loop, the attitude hold option is not activated. This causes a slight drift of simulated roll angle as seen in the lower left plot, but with this approach it is ensured that only the relevant LPV inner loop is compared. The disturbance reduction provided by the outer loop thus is only activated in flight test case. Due to the increased roll attitude (starting at $20 \mathrm{~s}$ ), a higher load factor is needed for a coordinated turn. As a result, load factor and elevator deflection in the simulation data are slightly increased compared to the flight test data. The pitch attitude and path angle show similar values and behavior. This indicates a good compliance of simulated and flight test behavior of the closed loop system.

\section{Conclusions}

In this work a Linear Parameter Varying based flight control system has been developed for a CS 25 certified aircraft. The obtained flight controller has been validated in an extensive flight test campaign, by means of a selection of pitch and roll maneuvers. The tested flight control algorithms have been proven to provide very good handling qualities according to the test pilot's feedback. This observation is also backed by 


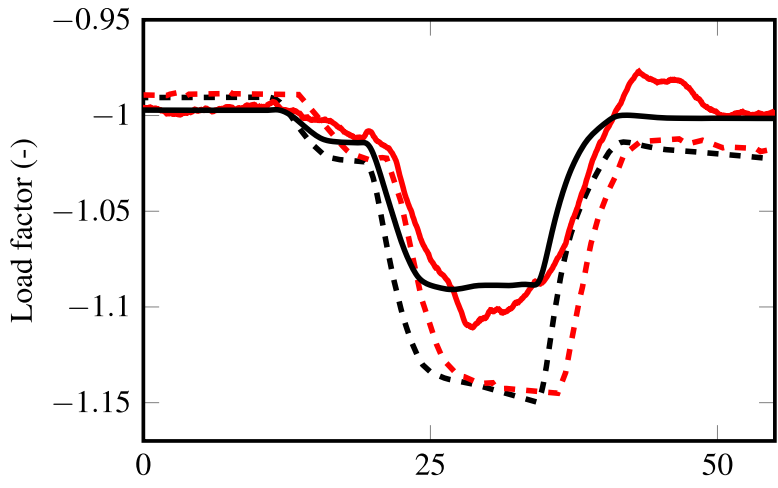

Resulting load factor command ( $\longrightarrow$ ) and response ( $\square$ ).

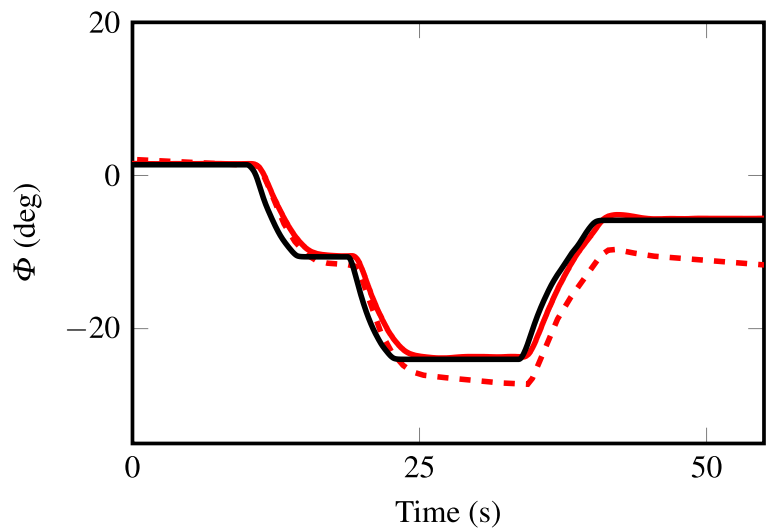

Integrated roll rate command ( $\longrightarrow$ ) and bank angle response ( - ) for flight test data, bank angle response (- - - ) for simulation.

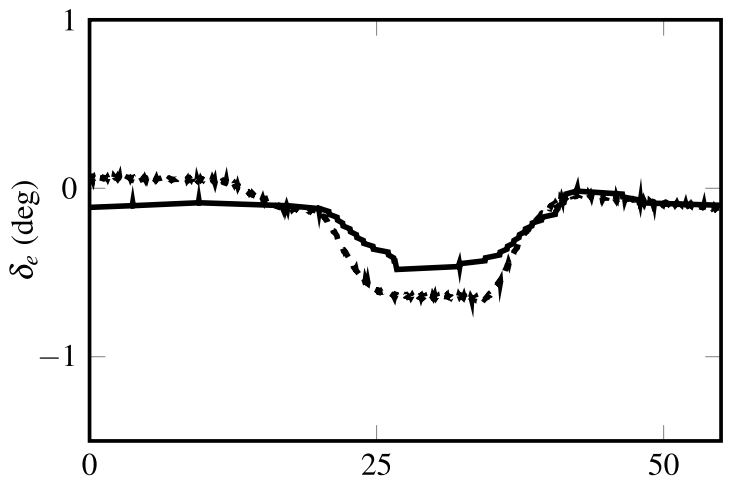

Elevator deflection relative to trim position.

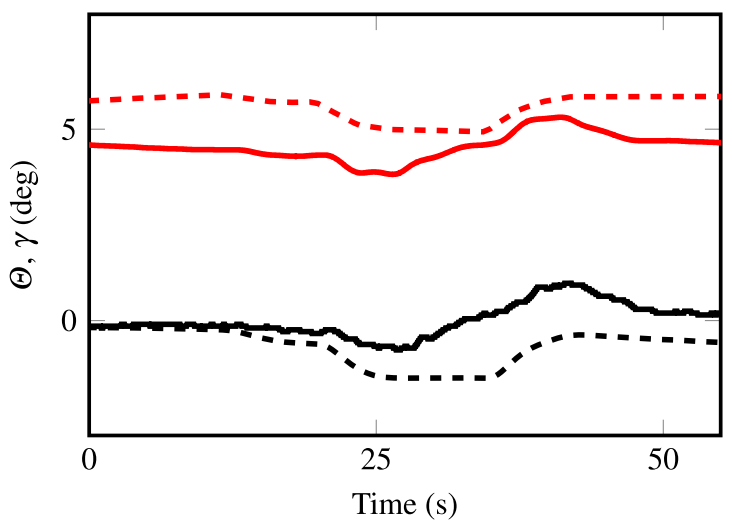

Pitch attitude ( $(-)$ ) and flight path angle ( - ).

Fig. 18 Simulation and flight test data of a load factor response during a roll maneuver at 95 kts VTAS. Command ( $\longrightarrow$ ) and response values (—) are color coded, flight test data are solid and simulation data dashed curves

the evaluation of test data. The gain scheduling feature of the controller, which is an intrinsic property due to the design process, has been verified in flight through maneuvering at different airspeeds. Finally, configuration changes were used for demonstration of satisfactory robustness of the control laws against unknown model changes.

Acknowledgements Open Access funding provided by Projekt DEAL. The authors would like to thank the following persons from Delft University of Technology (TUD) and DLR's Institute of System Dynamics and Control for their support: - Alexander in 't Veld and Tjipke van Netten (TUD), test / safety pilots of PH-LAB campaign who gave also valuable feedback on handling qualities of the controller - Olaf Stroosma (TUD) for providing and helping with the DUECA implementation and GUI design - Menno Klaassen (TUD), for his assistance before and during the flight campaign - Tobias Bellmann, Sebastian Kümper and Andreas Seefried (DLR) for their support during the RMS experiments - Richard Kuchar, Daniel Milz and Reiko Müller (DLR) for their support during the flight test execution.

\section{Compliance with ethical standards}

Conflict of interest The authors declare that they have no conflict of interest.

Open Access This article is licensed under a Creative Commons Attribution 4.0 International License, which permits use, sharing, adaptation, distribution and reproduction in any medium or format, as long as you give appropriate credit to the original author(s) and the source, provide a link to the Creative Commons licence, and indicate if changes were made. The images or other third party material in this article are included in the article's Creative Commons licence, unless indicated otherwise in a credit line to the material. If material is not included in the article's Creative Commons licence and your intended use is not permitted by statutory regulation or exceeds the permitted use, you will need to obtain permission directly from the copyright holder. To view a copy of this licence, visit http://creativecommons.org/licenses/by/4.0/. 


\section{References}

1. Apkarian, P., Gahinet, P., Becker, G.: Self-scheduled $\mathrm{H}_{\infty}$ control of linear parameter-varying systems: a design example. Automatica 31(9), 1251-1261 (1995). https://doi.org/10.1016/00051098(95)00038-x

2. Bates, D., Postlethwaite, I.: Robust Multivariable Control of Aerospace Systems. Control And Simulation. DUP Science, Singapore (2002)

3. Bellmann, T., Heindl, J., Hellerer, M., Kuchar, R., Sharma, K., Hirzinger, G.: The DLR robot motion simulator part I: design and setup. In: IEEE International conference on robotics and automation (2011). https://doi.org/10.1109/icra.2011.5979913

4. Bihrle, W.J.: A handling qualities theory for precise flight path control. Tech. Rep. data, Air Force Flight Dynamics Laboratory, Patterson Air Force Base, Ohio, USA (1966)

5. Braven, S.d., Verspay, J.: Identification of the servo actuated flight control system of the Cessna Citation II. Tech. Rep. VM-94006, National Aerospace Laboratory NLR (1994)

6. Brockhaus, R., Alles, W., Luckner, R.: Flugregelung, 3., neu bearb. aufl. edn. Berlin Heidelberg

7. European Aviation Safety Agency: Certification Specifications and Acceptable Means of Compliance for Large Aeroplanes CS-25 (2018)

8. Grondman, F., Looye, G., Kuchar, R.O., Chu, Q.P., Van Kampen, E.J.: Design and flight testing of incremental nonlinear dynamic inversion-based control laws for a passenger aircraft. In: 2018 AIAA Guidance, Navigation, and Control Conference, American Institute of Aeronautics and Astronautics, Kissimmee, Florida (2018). https://doi.org/10.2514/6.2018-0385

9. Hjartarson, A., Seiler, P., Packard, A.: LPVTools: a toolbox for modeling, analysis, and synthesis of parameter varying control systems. IFAC-Pap. OnLine 48(26), 139-145 (2015). https://doi. org/10.1016/j.ifacol.2015.11.127

10. van den Hoek, M.A., de Visser, C.C., Pool, D.M.: Identification of a Cessna Citation II Model Based on Flight Test Data. In: Advances in Aerospace Guidance, Navigation and Control, pp. 259-277. Springer, Cham (2018). https://doi.org/10.1007/978-3319-65283-2_14

11. Keijzer, T., Looye, G., Chu, Q., Van Kampen, E.J.: Design and Flight Testing of Incremental Backstepping based Control Laws with Angular Accelerometer Feedback. In: 2019 AIAA Guidance, Navigation, and Control Conference. American Institute of Aeronautics and Astronautics, San Diego, California (2019). https:// doi.org/10.2514/6.2019-0129

12. van der Linden, C.A.A.M.: Dasmat-Delft University Aircraft Simulation Model and Analysis Tool: A Matlab, Simulink Environment for Flight Dynamics and Control Analysis (Series 03 - Control and Stimulation, No 03). Delft Univ Pr (1998)

13. Lu, P., Van Eykeren, L., Van Kampen, E.J., De Visser, C., Chu, Q.: Aircraft inertial measurement unit fault identification with application to real flight data. J. Guid. Control Dyn. 38, 2467-2475 (2015). https://doi.org/10.2514/1.G001247

14. Muis, A., Oliveira, J., Mulder, J.A.: Development of a flexible flight test instrumentation system. In: 17th SFTE (EC) Symposium. Amsterdam, Netherlands (2006)

15. van Paassen, M.M., Stroosma, O., Delatour, J.: Dueca - datadriven activation in distributed real-time computation (2000). https://doi.org/10.2514/6.2000-4503

16. Papageorgiou, G., Glover, K.: Design of a robust gain scheduled controller for the high incidence research model. In: Guidance,
Navigation, and Control Conference and Exhibit. American Institute of Aeronautics and Astronautics, Portland, Oregon (1999). https://doi.org/10.2514/6.1999-4276

17. Papageorgiou, G., Glover, K., D’Mello, G., Patel, Y.: Taking robust LPV control into flight on the VAAC Harrier. In: Proceedings of the 39th IEEE Conference on Decision and Control (Cat. No.00CH37187), vol. 5, pp. 4558-4564. IEEE, Sydney, Australia (2000). https://doi.org/10.1109/CDC.2001.914633

18. Pfifer, H.: LPV/LFT Modeling and its Application in Aerospace, 1, aufl edn. Luftfahrt. Dr. Hut, München (2013)

19. Pfifer, H., Hecker, S.: LPV controller synthesis for a generic missile model. In: 2010 IEEE International Conference on Control Applications, pp. 1838-1843. IEEE, Yokohama, Japan (2010). https://doi.org/10.1109/CCA.2010.5611127

20. Pollack, T., Looye, G., Van der Linden, F.: Design and flight testing of flight control laws integrating incremental nonlinear dynamic inversion and servo current control. In: 2019 AIAA Guidance, Navigation, and Control Conference. American Institute of Aeronautics and Astronautics, San Diego, California (2019). https://doi.org/10.2514/6.2019-0130

21. Saupe, F., Werner, H., Weltin, U., Kreuzer, E.: Linear Parameter Varying Control Design for Industrial Manipulators, FortschrittBerichte VDI Reihe 8, Mess-, Steuerungs- und Regelungstechnik, vol. 1223. VDI-Verl, Düsseldorf (2013)

22. Schug, A.K., Seiler, P., Pfifer, H.: Robustness margins for linear parameter varying systems. AerospaceLab 13 (2017). https://doi. org/10.12762/2017.AL13

23. Skogestad, S., Postlethwaite, I.: Multivariable Feedback Control: Analysis and Design, 2nd edn. Wiley, Chichester (2005)

24. US Department of Defense: MIL-F-1797C: Flying Qualities of Piloted Aircraft (1997)

25. Weiser, C., Ossmann, D., Heller, M.: In-Flight Validation of a Robust Flight Controller Featuring Anti-Windup Compensation. In: 2018 Atmospheric Flight Mechanics Conference. American Institute of Aeronautics and Astronautics, Atlanta, Georgia (2018). https://doi.org/10.2514/6.2018-2982

26. Weiser, C., Ossmann, D., Kuchar, R., Looye, G.: Design and Verification of a Linear Parameter Varying Control Law for a Transport Aircraft. In: 5th CEAS Specialist Conference on Guidance, Navigation \& Control. Milan, Italy (2019)

27. Weiser, C., Ossmann, D., Kuchar, R.O., Müller, R., Milz, D.M., Looye, G.: Flight testing a linear parameter varying control law on a passenger aircraft. In: AIAA Scitech 2020 Forum. https://doi. org/10.2514/6.2020-1618

28. Wu, F.: Control of Linear Parameter Varying Systems. PhD Thesis, University of California, Berkely (1995)

29. Wu, F., Yang, X.H., Packard, A., Becker, G.: Induced $\mathrm{L}_{2}$-norm control for LPV systems with bounded parameter variation rates. International Journal of Robust and Nonlinear Control 6(9-10), 983-998 (1996). https://doi.org/10.1002/(sici)1099-1239(19961 1)6:9/10<983::aid-rnc263>3.0.co;2-c

30. Zaal, P., Pool, D., in 't Veld, A., Postema, F., Mulder, M., van Paassen, M., Mulder, J.: Design and certification of a fly-by-wire system with minimal impact on the original flight controls. In: AIAA Guidance, Navigation, and Control Conference. American Institute of Aeronautics and Astronautics, Chicago, Illinois (2009). https://doi.org/10.2514/6.2009-5985

Publisher's Note Springer Nature remains neutral with regard to jurisdictional claims in published maps and institutional affiliations. 